\title{
O PARADOXO DA FICÇÃO HISTÓRICA DO POVO LUSITANO
}

\author{
THE PARADOX OF HISTORICAL FICTION OF PEOPLE LUSITANO
}

\author{
Sirlene Cristófano ${ }^{1}$
}

\begin{abstract}
Resumo
A ficção histórica aparece no século XIX, quando a História adquire o estatuto de "ciências" para proporcionar o entendimento do desenvolvimento da sociedade, assim como de sua cultura. Para tal, a História é utilizada também para ficcionar narrativas e nos dar diferentes interpretações dos fatos. As ficções históricas, portanto, ao combinar fatos da história com a ficção dão-nos a explicação para um determinado conhecimento através de muitas técnicas narrativas. A ficção histórica adapta-se num paradoxo: afirma-se da ficção e testa a sua veracidade. Partindo deste ponto, este artigo pretende mostrar através do romance histórico português Inês de Portugal, de João Aguiar, e do conto «Teorema» de Herberto Hélder, a imagem mítica de Inês de Castro e o louco amor de D. Pedro em busca de vingança, observando a dimensão adquirida deste episódio de amor trágico na Cultura e na Literatura Portuguesa.
\end{abstract}

Palavras-chave: Ficção Histórica. Literatura. História. Mito.

\begin{abstract}
The historical novel appears in the nineteenth century, when history acquires the status of "science" to provide an understanding of societal development as well as their culture. To this end, history is also used to give us into fiction narratives and different interpretations of facts. The historical novels, therefore, to combine the facts of history coma fiction give us an explanation for certain knowledge through many narrative techniques. The historical fiction fits into a paradox: it is said of fiction and test their veracity. From this point, this article highlights the historical novel by Portuguese Inês de Portugal of Joao Aguiar, and the tale Theorem of Herbert Helder, the mythical image of Ines de Castro and crazy love of D. Pedro out for revenge, noting the scale gained from this episode of tragic love in History and Literature.
\end{abstract}

Key words: Historical Fiction. Literature. History. Myth.

\section{Introdução}

Falar sobre D. Inês de Castro e consequentemente de seu romance com D. Pedro é função ousada. Tornam-se rapidamente aparentes as dificuldades da empresa quando se tenta

${ }^{1}$ Doutoranda em Estudos de Literatura e Culturas Românticas, pela Faculdade de Letras da Universidade do Porto, FLUP, (2011), Mestre em Estudos Literários, culturais e Interartes, pela Faculdade de Letras a Universidade do Porto - FLUP, Portugal (2009). Pós-graduanda em Literatura pelo Centro Universitário UNIFIO, Br (2002) e formada em Letras pela mesma instituição (2001). Email: sirlene.cristofano@gmail.com 
estabelecer uma cronologia segura dos principais passos da trajetória de ambos. É missão, senão infactível, pelo menos de consequências duvidosas. Lidamos com uma relação marginal de um infante com a dama de honra de sua esposa, a qual se transferiu igualmente para o universo da escrita, não tendo deixado grandes reconhecimentos nos textos contemporâneos.

De acordo com José António Saraiva (s.d.), a realidade dos fatos da vida de D.Inês de Castro evidencia-nos que esta foi uma nobre galega, amada pelo futuro rei Pedro I de Portugal, com quem teve quatro filhos. Foi assassinada às ordens do pai deste, Afonso IV.

Inês era filha natural de Pedro Fernandes de Castro, mordomo-mor do reiAfonso XI de Castela, e de uma dama portuguesa, Aldonça Lourenço de Valadares. O seu pai, neto bastardo de Sancho IV de Castela, era um dos fidalgos mais influentes do reino de Castela.

Em 1333 aconteceu o casamento do D. Pedro, herdeiro do trono português com Constança Manuel. Mas seria uma das damas de honor de Constança, D. Inês de Castro, por quem D. Pedro viria a apaixonar-se. Esse romance começou a ser criticado na corte e pelo próprio povo. Sob a alegação da moralidade, rei D. Afonso IV não aceitava esta relação, não só por motivos de convencionalismo, mas também devido à amizade íntima de D. Pedro com os irmãos de D. Inês - Fernando de Castro e Álvaro Pirez de Castro. Sentindo-se perturbados pelos irmãos Castro, os nobres da corte portuguesa coagiram o rei D. Afonso IV a afastar esta influência do seu herdeiro. Assim, em 1344 o rei mandou expatriar Inês no castelo de Albuquerque, na fronteira castelhana. No entanto, a distância não teria apagado o amor entre Pedro e Inês.

No ano seguinte, D. Constança morreu ao dar à luz e, viúvo, D.Pedro mandou Inês regressar do exílio e os dois foram viver juntos em sua casa, o que provocou grande indignação na corte, para enorme contrariedade de El-Rei seu pai. Começou então um atrito entre o rei e o infante.

D. Afonso IV tentou atenuar a situação casando novamente o seu filho com uma dama de sangue real. Mas Pedro rejeitou esse projeto, argumentando que sentia ainda muito a perda de sua mulher Constança e que não conseguia ainda pensar em novo casamento. No entanto, fruto deste relacionamento, Inês foi tendo filhos de D. Pedro e o nascimento destes veio agravar a situação. Além do mais, circulavam mentiras de que os Castros maquinavam para assassinar o infante D. Fernando, herdeiro de D. Pedro, para o trono português passar para os filhos de Inês de Castro.

Depois de alguns anos, Pedro e Inês tinham retornado a Coimbra e se acomodaram no Paço de Santa Clara. Havia boatos de que D. Pedro tinha se casado sigilosamente com Inês. 
Na família real, uma circunstância deste tipo assumia intensas implicações políticas. O rei D. Afonso IV decidiu que a melhor solução seria matar a dama galega.

A 7 de Janeiro de 1355, o rei rendeu-se às pressões dos seus conselheiros e do povo e, aproveitando o afastamento de Pedro numa excursão de caça, enviou Pêro Coelho, Álvaro Gonçalves e Diogo Lopes Pacheco para matarem Inês de Castro em Santa Clara.

A morte de Inês gerou a revolta de D. Pedro contra D. Afonso IV. Após meses de conflagração e atrito a rainha D. Beatriz conseguiu interceder para selar uma paz em agosto de 1355.

A encantadora e bela D. Inês, a quem chamavam o "colo de garça", impressionou D. Pedro, ao que parece desde os primeiros momentos, e assim nasceu o enaltecido e infeliz romance entre os dois.

O episódio de Inês de Castro, corroborado como está pela documentação existente, não salvou à construção lendária - a da “miséria e mesquinha que depois de morta foi rainha”, como compôs Camões. Segundo esta lenda, D. Pedro, ao fazer desenterrar o corpo de Inês para colocá-lo no belíssimo túmulo de Alcobaça, mandou que, antes, assentassem o corpo num trono, com trajes reais a prestar-lhe vênia como rainha e a beijar-lhe a mão.

Não há um único documento coexistente declarando tal fato. Aliás, Inês foi desenterrada anos após a sua morte e não fora mumificada. Então imaginemos como estariam as condições dos seus restos mortais. Temos que levar em consideração que ela foi degolada: e que as "espadas de aço fino" foram fantasiadas por Camões. Inês foi executada por um algoz e seria um tanto impossível sequer colocá-la num trono.

A única certeza que podemos ter de todos esses fatos é que a fúnebre cerimônia da coroação e do "beija mão” à rainha morta, que D. Pedro teria exigido à sua corte e tornar-se-ia uma das cenas mais vívidas no imaginário popular, terá possivelmente sido introduzida nas narrativas do final do século XVI, depois da popularização do episódio de Os Lusíadas. Da vida de Inês Pires de Castro sabe-se pouco, a sua triste morte e o amor sem limites de D. Pedro e a forma como este quis eternizar esses amores alimentaram a poesia e a narrativa histórica, não deixando morrer o mito Inês de Castro.

Segundo Linda Hutcheon (1991), a linguagem do romance, em toda ficção, é representacional. Na metaficção o leitor passa a entender que toda ficção é um tipo de paródia - “uma repetição com diferença”. O universo (re)elaborado por ele deve então ser aceito como ficcional e de sua co-autoria. Através dessa percepção, sua ligação consciente com o texto se explica - apesar de livre para analisar, o leitor é responsável por sua interpretação. A autora evidencia que, na leitura da maioria das obras metaficcionais, o leitor toma consciência 
de que, desde que toda ficção é um tipo de reprodução da vida, não interessa quão possível ela pretenda ser; a ficção mais real e aceitável pode muito bem ser aquela que mais livremente reconheça sua ficcionalidade.

Hutcheon (1984) considera que cada ficção espessa em si origens de uma leitura egolatrista, de uma interpretação que modifica num aproveitamento simbólico ou metafórico do procedimento de articular um universo literário. O romancista pós-moderno pode dispensar uma relação do século XIX com seu leitor e fundamentar na convenção de onisciência que divulga um espelho da verdade empírica, como se o autor fosse um ser espiritual objetivo absoluto.

Pode também afastar um narrador do século XX que usa a concepção da primeira pessoa dentro de qualquer fato.

O que o escritor ficcional oferece ao seu leitor parece muito pouco: um relacionamento fundamentado na representação do processo real ao qual o autor está “acorrentado” no processo de trazer à vida os universos fictícios da sua fantasia na linguagem e através da mesma. Assim o leitor está, mais uma vez, associado a uma elaboração análoga, mas em ordem contrária, daquelas mesmas palavras ao mundo de sua imaginação.

Portanto, de acordo com Linda Hucheon (1991) a nomenclatura "metaficção historiográfica” explica as obras de ficção personalizadas por uma espécie de autoreferencialidade que não declina de uma ancoragem histórica e notavelmente algumas dessas narrativas têm como tema personagens ou fatos históricos, que serão submetidos “a abstração, à falsificação e a ficcionalização”.

A morte de Inês de Castro não somente como um facto histórico, mas também como uma imagem literária que a alçou ao mito, é um dos exemplos de des(re)construção da metaficção historiográfica. E nesta perspectiva, conforme diz Fátima Marinho, “A crença absoluta do facto histórico deixou de ser possível e abriu caminhos a vários tipos de apropriação do passado (...) novos caminhos de um gênero que se auto-recria originalmente” (MARINHO, 1999, p.15).

Essa nova forma de preocupação do texto, feita pelas fendas, reflete a tônica da narrativa contemporânea, marcada pela declaração do seu caráter ficcional. Averiguada a improbabilidade de apreensão do "real”, a veracidade que se busca é a verdade da ficção. Portanto, a ficção autoriza uma biografia em que se busca apenas a verdade do texto, relativizando-se a própria essência de “verdade”.

Desse modo, enquanto as remotas narrativas se caracterizavam por um ensaio de fundamentação, a pós-modernidade é marcada por uma valorização do sujeito. Assim, o 
passado histórico submete-se ao presente do narrador, numa desconstrução própria da pósmodernidade.

O gênero literário ficção histórica aparece mais fortemente no século XIX em plena expansão e desenvolvimento enquanto gênero, quando a História adquire o estatuto de “ciência”, razão para a compreensão do desenvolvimento social e cultural da humanidade. A História é utilizada de muitas formas e com diversos objetivos para ficcionar narrativas e a capacidade de se servir de personagens referenciais, criações e mitos - representativos de uma classe ou grupo social de uma determinada época - é convidativa devido à vasta opção de possibilidades em escapar a uma realidade pouco contemplativa e também de buscar uma nova ideia da realidade.

A existência de ficções históricas que nos podem dar diferentes expectativas e interpretações dos fatos - numa combinação da História com a ficção - satisfazem a curiosidade de um tempo ou lugar, dando-nos a explicação para um determinado acontecimento através de um vasto recurso narrativo, conforme nos explica David Carr, citado por Maria de Fátima Marinho, que “o passado pode ter variadas interpretações, mas não pode ser modificado, a verdade é que a explicação que dele for dada estará sempre condicionada pela construção ficcional da cultura de uma determinada época, tornando-se história interpretada” (MARINHO, 2004, p. 351).

Porém, a ação ligada aos conceitos contidos na definição vai originar contínuos problemas de (re) classificação. Assim entendido, tal como muda o conceito de História através dos tempos, muda também a interpretação dos autores dada a esse conceito. O conceito de ficção também é atingido por essas mesmas circunstâncias e assim podemos perceber que em cada momento se verifica uma nova adaptação ou demarcação da significação do romance histórico. Temos que abdicar de uma definição de ficção histórica alcançada e complacente, para reunir todas as narrativas que se utilizam da História. De acordo com a afirmação de Maria de Fátima Marinho, uma forma mais atual de compreendermos os fenômenos literários é abordar a ficção histórica sob a ótica do papel que a história desempenha nas ficções e também de que maneira são tratadas as personagens, as "Biografias [...] ou romances, como por exemplo, o de João Aguiar, os quais [...] constituem casos de desvio da História que o discurso do poder consagrou ao pôr a tônica em perspectivas diferentes, que podem passar pela atribuição da voz da narrativa à personagem biografada” (MARINHO, 2004, p. 351). Cabe-nos lembrar que o romance histórico é uma narrativa ficcionada e consequentemente classificada como histórico, porque a História e o 
real são os suportes dessa ficção. Assim, não devemos procurar da verdade histórica, pois essa "verdade” muda de acordo com o tempo e com a focagem que se constrói sobre ela.

Os autores preocupam-se em afirmar a verdade histórica que narram os casos em que os autores empíricos se assumem como selecionadores de diários ou outros documentos à disposição.

Em Portugal, nas últimas décadas, deparamo-nos com alguns desrespeitos a esse código, que apontam na direção de uma nova elaboração de História: autores como Fernando Campos, Augustina Bessa-Luís, Fernando Dacosta, entre outros, “criam a outra história, que é sempre imitação do passado, mas que nunca o podem nem pretendem o reproduzir” (MARINHO, 1999, p. 35).

O estudo do qual resulta este artigo aborda a imagem mítica de Inês de Castro através da escrita literária de Herberto Hélder e João Aguiar, respectivamente em «Teorema» e Inês de Portugal. Assim, observando a dimensão adquirida pelo mito inesiano na Cultura e na Literatura Portuguesa, dada a vasta produção literária - excessivamente em múltiplas focalizações - que mantém Inês de Castro ainda como um tema mítico recorrente em Portugal.

\section{Inês de Castro em Inês de Portugal}

A época atual possibilita o encontro de vários fatos que a literatura procura narrar «literatura e história» e com a troca de discursos, certificamo-nos que o passado e as suas verdades históricas podem ser exemplos para o presente. Esses comportamentos não permanecem afastados da ficção portuguesa no século XX e XXI.

As atuais ficções portuguesas apresentam muitos aspectos e vários pontos de olhar, intervenções de espaços e tempos que se combinam através dos discursos. João de Aguiar buscou nos cronistas medievais as justificações exemplares da sua ficção, onde também muitos outros escritores se foram apoiar. Esses cronistas medievais, como por exemplo Fernão Lopes e Rui de Pina, construíram os assuntos centrais do caso de amor entre D.Pedro e Inês de Castro. Nessas crônicas ajustam-se as ideias que, ao longo dos tempos, haveriam de criar a estória do Infante D. Pedro e Inês de Castro, transformando-a em matriz para outras narrativas. Cada uma das crônicas mostra uma realidade própria na exposição do caso.

Através da Crônica de D. Pedro, de Fernão Lopes, por exemplo, João Aguiar absorve da obra medieval a imagem do rei justiceiro para com seu povo. João Aguiar, de Inês de Portugal, afirma-nos que, "tal como na Crônica de D. Pedro de Fernão Lopes, a imagem do 
rei justiceiro, que o povo identifica como a imagem utópica do soberano pai, de um agente ideal da justiça terrena” (DELILLE, 2004, p. 197).

João Aguiar, ao buscar as várias matrizes, reconhece que a verdade historiográfica é uma questão interpretativa dos fatos e fundamenta as diferentes versões ao relacionar-se com a memória das personagens envolvidas e também da heroína através das lembranças de D. Pedro, conforme Gouveia Delille, quando nos afirma que "tal como nos outros romances de fundo histórico, o autor [...] segue muito de perto o discurso historiográfico canónico sobre o episódio em questão [...] e mostra estar bem informado acerca das leituras e interpretações dos historiadores mais recentes, nomeadamente no que diz respeito à desmontagem de traços e eventos de natureza meramente lendária” (DELILLE, 2004, p. 191).

No discurso de cada personagem, fica acessível a ligação do romance à palavra que o atualiza, na coerência de cada uma das falas, desponta-se uma particularidade de Eros e os muitos sentidos da paixão. A epígrafe da ficção sugere menos para a individualidade histórica que para a perspectiva ficcional: a particularidade de um caso que afrontou a morte. (FRANCO, 1989). Tal exceção é acentuada por D. Pedro a respeito do amor que oferecera e ainda consagra a Inês, deixando-nos claro quando afirma que, "nunca houve nem haverá no mundo amor como este” (AGUIAR, 197, p.9).

A cada momento, as ações régias comprovam a individualidade inigualável desse amor e, nas falas das demais personagens, se evidencia a peculiaridade dessa paixão. Embora ressaltando a lenda, a ficção não deixa de apelar para a história, para comprovar a tendência da literatura pós-moderna para a quebra das fronteiras entre o fato e o aparente. Como exemplo, temos a descrição do documento que celebra o acordo de paz entre o Infante e seu pai, por obra da rainha D. Beatriz. O documento é histórico, mas o uso que dele é feito torna-o literário: antecede a intenção do Infante de não ser fiel ao acordo efetuado, bem como os olhares atravessados que D. Pedro lança aos assassinos de Inês presentes na cerimónia, os quais completam a cena da leitura do documento com uma força dramática literária, segundo as palavras de Gouveia Delille ao citar Loesther, afirmando-nos que "realmente o que instigou a encenação teatral da história é o acerto de contas, não com aqueles que perpetraram o ato, mas com aqueles que justificaram e chancelaram” (DELILLE, 2004, p. 19).

Neste panorama, Inês de Portugal ressalta das obras literárias que comentaram o tema inesiano, destacando a tragédia, vigorando o desejo de vingança, assim como também nas "Trovas", de Garcia de Resende, das quais o romance contemporâneo traz para sua trama o assunto de uma imaginária voz que se ergue dos abismos tumulares em que se encontra o par Pedro e Inês. 
Este, com suas recordações, vive a aflição, a falta de sua amada, sentindo-se morto ele também, pois só se aceita vivo com as lembranças do passado, só se define em harmonia com a amada morta. Segundo Maria Manuela Gouveia Delille, “dadas as frequentes ‘ausências’ ou alheamentos de Pedro (...) entre trechos dos sentimentos íntimos desse rei que para si próprio se considera um fantasma " (DELILLE, 2004, p. 191).

Dadas essas considerações é da amargura da memória de Pedro que Inês se ergue, enquanto voz, e é do tema terrível que a eterna amada ressurge enquanto imortal, como nos mostra João Aguiar na sua obra "um fantasma dentro de uma fantasma, ambos num mundo de sombras, a recordar outro tempo em que viviam no mundo dos homens e sentiam na pele o calor do Sol, o vento e as carícias que um ao outro faziam” (AGUIAR, 1997, p.61).

Partindo da qualidade ficcional comprovada na constante solicitação à focalização interna, dá uma confiabilidade psicológica à aniquilação das dificuldades espaciais e temporais. Com isso, o romancista afirma a "veracidade" do narrado, por meio de exatidões espaciais. O que significa para alguns autores que,

Através de passos em psiconarração, ora por meio de monólogos, permite ao leitor o acesso à subjetividade das personagens, aos pensamentos e sentimentos mais íntimos; frequentes vezes o desdobrar dessa vida interior traduz-se nas evocações de cenas outrora testemunhadas por essa mesma personagem. (DELILLE, 2004, p. 75).

Em Inês de Portugal, os espaços subdividem-se em espaço real e espaço da memória. No primeiro, ocorrem as ações do presente da narrativa: acontece no dia em que chegam os prisioneiros e no dia seguinte em que o Rei vai fazer justiça em Alcanede, e depois, no dia em que junto à sua escolta, volta ao remoto espaço, onde se realizará o ato de justiça. No segundo, acontecem os episódios passados que a memória de um ou outro personagem traz à cena os sonhos oníricos, quando, por exemplo, D. Pedro sonha com a alcova do castelo de Monterrei. Afonso Madeira - seu conselheiro - preocupa-se com tais ausências, porque tem a consciência de que o rei sai do espaço real para o onírico, a fim de relembrar Inês na sua primeira noite de amor.

Também podemos dizer que D. Pedro, com sua sede de vingança, transforma os espaços de amor e morte num espaço de vingança e justiça ao relatar que "o espaço de amor que foi a Quinta das Lágrimas em múltiplas ficções anteriores torna-se um espaço tribunal, ameaçando transformar-se para os convidados/convocados em um espaço de morte, conforme observa Maria Manuela Gouveia” (DELILLE, 2004, p.75). 
O prolongamento espaço-temporal só se dá decorrente da memória das personagens convocadas por detalhes que estimulam a recordação. Assim, ao ouvir de João Afonso Tello que Inês "parecia inocente", Álvaro Pais recapitula que os irmãos foram visitá-la e que esta fora desmascarada. Ao ouvir o "som das completas", tem a memória ocupada pelo sarau do castelo de Lisboa em que ao som da cantiga de amor de El-Rei D. Dinis, toda a corte presenciara os olhares apaixonados lançados pelo Infante à Inês. Cada personagem, enquanto relembra, torna-se narrador onisciente, entrando no pensamento e nos desejos dos outros personagens, num jogo em que se acrescentam, se equilibram e se confrontam.

A ficção contemporânea contesta a posição de Inês como vítima inocente, caracterizações que lhe deram algumas outras obras literárias. Através de João Aguiar, deduzimos do conjunto dos atos em que a heroína é lembrada, como uma mulher apaixonada que em outros momentos se revela também ambiciosa como reciprocidade à ambição de seus irmãos. Podemos então complementar que o contradizer da inocência de Inês, que lança uma nova razão sobre os acontecimentos históricos é, na ficção, uma lembrança da suposição do povo. Trazida através do discurso de personagens, tal como o caso do bobo da corte, Martim personagem que foi pago por Álvaro Pais para escutar a conversa de Inês com seus irmãos ao expor a maneira maliciosa com que os Castros estimularam a ambição de Inês - através de uma fala estimulante com que interpreta as palavras e o riso de Inês - confirma como esta não ficara indiferente às intrigas dos irmãos ao ouvir: “ Atentai, Inês, que esse amor que o Infante vos tem é a vontade de Deus ordenando as vontades dos homens. Haveis de saber que o destino entregou nas vossas mãos. [...] uma coroa , Inês” (AGUIAR, 1997, p.32).

De forma crítica demonstra-se que tal título - Rainha de Portugal - nasce de artifício e de armadilhas dos Castros que aguçam a ambição da irmã, sugerindo-lhe que a sua futura magnificência fazia parte dos planos divinos.

Inês de Portugal apresenta-se dividida em três capítulos, os quais são antecipados por um salmo penitencial, em latim, que antecede cada fase da ação. A primeira, que tem por epígrafe De profundis clamo ad te, Domine, focaliza o desespero de D. Pedro e seu desejo de vingança contra Álvaro Gonçalves e Pero Coelho responsabilizados pela morte de Inês de Castro. As razões individuais e políticas são demonstradas pelas falas de seus conselheiros. Focaliza Álvaro Pais angustiado pelo sincero amor que devota a Pedro e o grande amor que tem por Portugal e que o faz colocar a salvação do reino "acima da salvação da alma do Rei." O personagem Álvaro Pais apresenta-se preocupado quanto à possibilidade do rei vir a quebrar o juramento, comprometendo assim, a sua soberania e boa fama dos reis de Portugal, 
afirmando que "todos dirão que os reis de Portugal e de Castela erram muito, indo contra as suas verdades” (AGUIAR, 1997, p.30).

Portanto, é a palavra que João de Aguiar desencadeia na ficção que alimenta a tragédia através de uma série de acordos que se concedem e que se desfazem por ação da palavra. O primeiro que se estabelece é a jura de eterno amor e de eterno serviço que D. Pedro dedica a Inês no momento da primeira noite de amor. Contudo, a vingança do rei seria entendida mal no Reino, pois representava a não obediência à palavra empenhada em Canavezes. D. Pedro justifica mostrando que o verdadeiro juramento foi o que fizera a Inês e que só esse era verdadeiro e que o pretendia cumprir. E assim, por lealdade a essa palavra, o rei será infiel ao outro juramento. Assim entendido, a tragédia da vingança concentra-se no começo entre as palavras ditas, comprometidas e/ou desacatadas, levando alguns personagens a recear a quebra da palavra dada pelo rei em Canavezes. Podemos verificar na voz de Afonso Tello, quando diz: “A mim (...) dói-me sobretudo que ele possa quebrar a sua palavra, que é feia cousa e pecado maior por ser palavra de Rei” (AGUIAR, 1997, p.29).

Essa preocupação tem explicação, porque cada quebra de contrato cria novos erros e ameaças que avançam para a vingança. A tensão criada a partir de prenúncios, sonhos, aviso ou profecias intensificam a expectativa e há a aparição agourenta da tragédia a partir de insinuações e perguntas deixadas no ar. Assim, as reticências apontam para silêncios decifrados e questionamentos, cujas respostas não são proferidas por medo de que se efetivem. Exemplificamos assim, através das meias palavras e silêncios do diálogo entre Conde de Barcelos e Álvaro Pais: “Sim, diz o conde, El Rei quer muito a Afonso Madeira. Álvaro Pais desafia esse embaraço: Muito. Demais. [...] o assunto perturba-os” (AGUIAR, 1997, p.39).

Insinuando, o romance adianta e justifica a fúria de D. Pedro contra seu escudeiro. Há, ainda, premonição mediante os símbolos, como a insistência na associação do vinho e do sangue, remetendo à fatalidade de que prazer e dor são sentimentos próximos. A partir dos pensamentos íntimos do rei, temos a certeza dos seus planos inevitáveis de vingança. Depois de beber o vinho e de ver sua face furiosa refletida no vermelho líquido, o Rei pensa na vingança, de modo que o vinho adianta o próximo derramamento de sangue, fazendo-o excitar-se com as lembranças. Outra suposição da futura vingança é o sangue da iniciação amorosa de Inês, absorvido pelo linho do lençol. D. Pedro visto como: “um lobo esfaimado espreitando o rebanho no fundo do Inverno...” (AGUIAR, 1997, p.49) é comparado a animais violentos, o que lhe caracteriza a personalidade malvada, que ao longo do romance, funciona como vestígio de sua cruel vingança. 
No segundo capítulo, o enredo é encabeçado com o salmo Misereatur tui omnipotens Deus, em que se ressalta a ação justiceira do Rei, quando ao deslocar-se para Alcanede juntamente com sua corte, condena seu escudeiro favorito acusado de adultério. Cena como esta e a decapitação dos escudeiros Gil Fernandes e Rui Vasques, atua como negociação da ação de vingança sobre Álvaro Gonçalves e Pero Coelho, fazendo de cada uma delas a antecipação da justiça, fato de que o próprio vingador tem consciência, quando se explica dizendo viver sedento de sangue em prol de vingança.

Ainda neste segundo capítulo, surgem intercaladas com a recordação do ato em que Inês suplica misericórdia e mesmo assim, fora executada. No terceiro capítulo, o que focaliza o traslado dos restos de Inês do convento de Santa Clara para o mosteiro de Alcobaça é antecipado com o canto litúrgico Per omnia saecula saeculorum. Este capítulo termina com a formalidade de reconhecimento do possível casamento secreto dos amantes do Mondego. Os salmos que precedem cada capítulo preparam para a tragédia do amor e também para a consagração do mesmo, transformando-o em mito, que age sobretudo onde a paixão é sonhada como ideal, “onde a sua fatalidade é chamada, imaginada como uma bela e desejável catástrofe...” (ROUGEMONT, 1982, p.20).

E assim, consumada a vitória mítica do amor sobre a morte - a justiça final - D. Pedro ao caminhar na direção do portal do mosteiro “solta um rugido fundo, discreto, um 'Aaah' íntimo de satisfação... [e] ao sentir que finalmente cumprira a sua missão e ao ser aprovado e aplaudido pelo seu povo, ergue a taça para que lhe deitem mais vinho (...)” (AGUIAR, 1997, p.28). Aqui se focalizam os dois momentos da narrativa inesiana: seu desfavorecido amor e seu fatal fim, como também a sua exaltação após a morte.

É importante ressaltar que, a ficção é movida por duas perspectivas contraditórias sobre a morte de Inês: a de Álvaro Pais e a de D. Pedro. A perspectiva de Álvaro Pais acentua a necessidade política dessa morte e D. Pedro a vê como uma injustiça e uma barbárie. Essas visões incompatíveis estão relacionadas com a visão dupla da imagem de Inês e D. Pedro em Inês de Portugal, o que significa que, “João Aguiar em seu romance questiona de forma implícita, as representações mitográficas tradicionais, entrando em ruptura com os esquemas cognitivos que o leitor comum associa a estas duas figuras históricos lendárias” (DELILLE, 2004, p.193).

A representação da figura de D. Pedro tem como base a Crônica de Fernão Lopes o que não revela obscuridade, porém existem traços que pesam de forma diferente na imagem do rei: o amor incondicional, o sofrimento pela perda da amada e a busca incansável pela vingança/justiça ligada ao eterno amor. 


\section{Inês de Castro em «Teorema»}

Em Um Poço sem Fundo, há os mais diversos aspectos atribuídos à figura mítica de Inês de Castro. Marinho relata na sua obra crítica, os nomes de muitos autores que deram a Inês de Castro as mais diversas caracterizações. Segundo a autora, Helberto Hélder, por exemplo, atribui a D. Pedro a função de transformar os fatos históricos, quando este "fez transportar o cadáver da amante de uma ponta à outra do país, às costas do povo, entre tochas e cânticos” (HELDER, 1980, p.120), aproveitando-se assim da imagem de Inês e utilizando-a como um recurso para a construção de um consciente colectivo nacional.

Assim como João Aguiar distancia o ponto de focalização régia no seu romance, Herberto Hélder também descentra o ponto de focalização de Inês de Castro, o que modifica os dados do problema, pois não se trata de uma nova interpretação, mas sim de ponto de vista do mito. Tal procedimento descentralizador da argumentação régia foi iniciado com o seu conto «Teorema», em que a focalização não é mais a de D. Pedro ou a de D. Afonso IV e seus conselheiros, mas sim a do assassino Pero Coelho. Em «Teorema», "D. Inês não é mais vítima [...] só interessa a morte de Pero Coelho narrada pelo próprio e a suas causas que presidiam ao seu ato criminoso" (MARINHO, 1982, p.80).

O conto é, necessariamente, a apresentação teorética de que a morte de Inês era a condição primeira, para que o amor de D. Pedro não se extinguisse e para que o casal de apaixonados fosse transformado em mito e eternizado no código literário. Pero Coelho, enquanto personagem de «Teorema», tem conhecimento de seu papel, por isso repete: "Senhor [...] agradeço-te a minha morte. E ofereço-te a morte de D. Inês. Isto era preciso, para que o teu amor se salvasse” (HELDER, 1980, p.104).

A morte em «Teorema» segmenta-se em duas formas: como base do mito, pois o assassino Pero Coelho morre por ter imortalizado o amor; e também na forma de caminho para o livramento do desejo da morte, sendo neste conto, vista como uma imortalização da vida. Pero Coelho e o rei conseguem libertar esse desejo inconsciente, pois para ambos nada é incorruptível como a morte de D. Inês. (MARINHO, 1982, p.80). O poeta não escreve uma história referida pela História, mas sim sobre a História do mito. O narrador aponta as autênticas razões, deixando claro que foi o seu ato que criou o mito:

Pero Coelho, ao declarar que matou por amor do amor, demonstra-nos que além da primordialidade da morte de Inês, as actuações cerimoniais de vingança do rei, são também acções fundamentais para a iniciação do mito. (MARINHO, 2005, p.326). 
O personagem sabe que foi a morte de Inês que eternizou o seu infeliz amor, por isso, na hora da vingança de D. Pedro, agradece-lhe a própria morte e lhe oferece a de Inês, como se fora o fundamental de um ritual necessário para, imediatamente, se tornar a vítima de um sofrimento igualmente necessário: “Não me interessa o Reino. Matei-a para salvar o amor do rei” (HELDER, 1980, p.104).

Toda a cena da vingança de D. Pedro, com a retirada do coração do assassino para depois o comer diante da população, assume o sentido figurado de uma cerimônia sagrada, em que o canibalismo é semelhante à comunhão dos corpos, eternizando a morte e tornando-a vida. Um outro elemento fundamental usado em «Teorema» para o estabelecimento do mito é o deslocamento utilizado por Hélber, quando o rei D. Pedro fez transportar o cadáver da amante de uma ponta à outra do país, as costas do povo, entre tochas e cânticos.

Os homens não podem viver sem mitos, histórias ou qualquer outra imagem sobre as quais possam imaginar-se e reconhecer-se. Os fatos da História deixados pelo tempo e pelos historiadores sobre Inês de Castro, apesar de terem alguma relevância no conto de Herberto Hélder, não importam tanto em «Teorema» quanto eternizar o amor, destruindo-o e logo após recriando-o. Portanto, a história do amor de Inês e D. Pedro é eternizada a partir da morte da heroína.

Em «Teorema», o amor vive através do crime e do sangue e a conjuntura amorosa adquire-se enquanto tragédia mortal. A temática do amor existe no conto apenas como representação sem sentido concreto e o amor em «Teorema» não será, portanto, entre Inês e o rei, mas sim o amor na percepção de Pero Coelho, do seu sangue doado para a História, para a imortalização do amor enquanto mito. Assim entendido, Herberto Hélder retoma a teoria avançada por Garcia de Resende, ao escrever que nada é tão decente como a morte de D.Inês e foi a sua morte e triunfo que lhe seguiram a elaboração do mito com todas as capacidades e competências que lhe são inerentes.

\section{Considerações Finais}

Interessa-nos neste artigo destacar que as obras corajosas e arrojadas, como Inês de Portugal, de João Aguiar e «Teorema», de Herberto Hélder, procuram (re)apresentar alguma realidade histórica, porém afigurando-se também de uma realidade ficcional de cada ficção. Essas obras portuguesas são ficções históricas e o material que esses autores utilizam é o mesmo, apenas o efeito final é diferente - fruto do acolhimento dado à História e/ou à história 
- e também representantes do terceiro momento da ficção histórica e significante de um primeiro... Tempo inovador da Literatura.

Portanto, partindo da leitura de livros teóricos, concluímos que, em sua ficção histórica, Inês de Portugal, João Aguiar individualizou a personagem não como uma vítima inocente e indefesa, mas como uma mulher atraente e apaixonada que, apesar de amar o rei, foi contaminada pela cobiça, através de seus irmãos, os Castro. João de Aguiar retratou a influência pós morte que Inês teria exercido sobre o D. Pedro, o que se enquadrava no seu senso de justiça e que originou o tema trágico da vingança.

Já no conto «Teorema», de Herberto Hélder, a nossa pesquisa mostrou-nos como a ficção des (re) construiu uma nova imagem de Inês de Castro, transformando-a num mito inesquecível, já agora, numa expectativa diferente: que o amor de Inês e D. Pedro foi imortalizado a partir da morte da "bela garça", que o amor vive através do crime e do sangue modificando a condição amorosa numa tragédia mortal. O amor em «Teorema» não será, portanto, entre Inês e o rei, mas sim o amor na concepção de Pero Coelho, do seu sangue consagrado para a História.

Com as suas ficções, João Aguiar e Herberto Hélder inovam e des (re) constróem o mito de Inês e notabilizam a ficção portuguesa. Sendo importante e afamado no rol dos acontecimentos da História de Portugal, o romance entre Inês de Castro e D. Pedro é também, sem dúvida, um dos fatos mais evocados por escritores nacionais e estrangeiros.

\section{Referências}

AGUIAR, João. Inês de Portugal. Lisboa: Asas Editores, 1997.

COUTO, M. A. Rocha. Romance Histórico. 1995. Dissertação (Mestrado). Porto, 1995.

ELIADE, Mirce. Mito e realidade. São Paulo: Perspectiva, 1972.

DELILLE, M. M. Gouveia. Ficção e História: O episódio de Inês de Castro num romance português e num drama alemão contemporâneo. Porto : Actas do Colóquio Internacional Lit. e História, 2004.

FRANCO, Irley. "Eros Platônico e Moderno”, In: O que nos faz pensar. Cadernos do Departamento de losoa da PUC, Rio de Janeiro, n. 1, p. 15-28, 1989.

HELDER, Herberto. Teorema. In: Os Passos em Volta. 4. ed. Lisboa: Assírio e Alvim, 1980.

HUTCHEON, Linda. Narcissistic narrative : the metaficcional paradox. London: Routledge, 1984. 
Poética do pós-modernismo. Rio de Janeiro : Imago Editora, 1991.

MARINHO, Maria de Fátima. Herberto Hélder: a obra e o homem. Lisboa: Ed. Arcádia, 1982.

O discurso da história e da ficção : modificação e permanência. Porto: Actas do Colóquio Internacional - Literatura e História, 2004.

O Romance histórico em Portugal. Porto: Campo das Letras, 1999.

As máscaras de Inês. In: Um poço sem fundo. 1. ed. Porto: Campos da Letras, 2005.

PIGLIA, Ricardo. Memória e Tradición. In: ABRALIC, Literatura e memória cultural, São Paulo: Anais... Belo Horizonte, 1991.

REIS, Carlos. Os mitos do amor. Lisboa : Livros Horizonte, 2001.

ROUGEMONT, Denis de. O amor e o ocidente. Lisboa: Ed.Moraes, 1982.

SARAIVA, António José. História da literatura portuguesa. 5. ed. Porto: Porto, [19--].

WIKIPÉDIA: a enciclopédia livre, disponível em:

<http://pt.wikipedia.org/wiki/In\%C3\%AAs_de_Castro> Acessado em 12 Maio 2009. 